\title{
Lost in Translation: NIH Funding for Family Medicine Research Remains Limited
}

\author{
Brianna J. Cameron, MPH, Andrew W. Bazemore, MD, MPH, \\ and Christopher P. Morley, PhD, MA
}

Departments of Family Medicine (DFMs) in the United States consistently received around $0.2 \%$ of total research funding dollars and $0.3 \%$ of all awards awarded by the National Institutes of Health (NIH) across the years 2002 to 2014 . We used the NIH Reporter tool to quantify the amount of funding and the number of grants received by DFMs from the NIH from 2002 to 2014, using criteria similar to those applied by previous researchers. NIH funding to DFMs as remained fairly consistent across the time period, at roughly $0.2 \%$ of total NIH funding and $0.3 \%$ of total grants awarded. Changing these proportions will likely require considerable effort to build research capacity within DFMs and their frontline practice research networks, and to shift policymaker and funder perceptions of the value of the FM research enterprise. (J Am Board Fam Med 2016; 29:528-530.)

Keywords: Awards \& Prizes, Family Practice, Grants, Primary Health Care, Research

Among medical specialties, Family Medicine (FM) provides care across perhaps the broadest spectrum of conditions, settings, and populations, while hav-

This article was externally peer reviewed.

Submitted 10 February 2016; revised 1 April 2016; accepted 18 April 2016.

From Central New York Master of Public Health Alumnus, SUNY Upstate Medical University, Syracuse, NY (BJC); the Robert Graham Center for Policy Studies, Washington, DC (AWB); and the Departments of Family Medicine, Public Health \& Preventive Medicine, and Psychiatry \& Behavioral Sciences, SUNY Upstate Medical University, Syracuse (CPM).

Funding: This project was supported in part by the Health Resources and Services Administration of the U.S. Department of Health and Human Services under grant number D54HP23297, "Academic Administrative Units," for roughly \$2000 (total award amount \$154,765; 90\% financed with nongovernmental sources), corresponding to the amount of effort dedicated to this project by the lead author (BJC).

Conflict of interest: none declared.

Disclaimer: This information or content and conclusions are those of the authors and should not be construed as the official position or policy of, nor should any endorsements be inferred by, the Health Resources and Services Administration, the U.S. Department of Health and Human Services, or the U.S. government.

Corresponding author: Christopher P. Morley, PhD, MA, Department of Family Medicine, SUNY Upstate Medical University, 750 East Adams St, MIMC 200, Syracuse, NY 13066 (E-mail: morleycp@upstate.edu).

\footnotetext{
See Related Commentary on page 525
}

ing one of the smallest research enterprises. Departments of FM (DFMs) in the United States consistently received around $0.2 \%$ of total research funding dollars and $0.3 \%$ of all awards awarded by the National Institutes of Health (NIH) across the years 2002 to 2014 .

As the largest group of physician providers in primary care, the nation's largest health care delivery platform, ${ }^{1} \mathrm{FM}$ offers considerable potential to conduct original and translational ${ }^{2}$ research that informs achievement of the triple aim. ${ }^{3}$ However, the FM research enterprise receives little funding from the world's largest biomedical research funder, the NIH, when compared with its specialty peers. ${ }^{4}$ Previous analyses from the Robert Graham Center determined that DFMs received $\$ 187$ million of the $\$ 95$ billion in total research funding dollars awarded by the NIH between 2002 to $2006 .{ }^{5}$ Since that analysis, it is unknown whether the Patient Protection and Affordable Care Act, NIH Roadmap efforts to increase translational research, or increased national attention to primary care has altered NIH funding to FM.

Developed since the previous study by the Robert Graham Center, the NIH RePORTER tool ${ }^{5}$ provides a central repository of information on all $\mathrm{NIH}$ awards, including the investigator and institution assigned to each. We used this resource to 
Table 1. National Institutes of Health Grant Dollars (in Millions) and Number of Grants Awarded to Departments of Family Medicine from 2002 to 2014

\begin{tabular}{lccc}
\hline & $2002-2006^{*}$ & $2007-2010$ & $2011-2014$ \\
\hline Total grant dollars received by FM, 2014 & $\$ 57$ million & $\$ 76$ million & $\$ 71$ million \\
Total grant dollars awarded by NIH, 2014 & $\$ 28,451$ million & $\$ 38,002$ million & $\$ 32,985$ million \\
Total NIH grant dollars awarded to FM (\%) & 0.20 & 0.20 & 0.22 \\
Total grants received by FM (n) & 170 & 224 & 192 \\
Total grants awarded by NIH (n) & 60,227 & 71,777 & 65,603 \\
Total NIH grants awarded to FM (\%) & 0.28 & 0.31 & 0.29 \\
\hline
\end{tabular}

${ }^{*}$ Differs slightly from the findings of Lucan et al, ${ }^{4}$ who used data directly from the Office of Extramural Research.

FM, family medicine; NIH, National Institutes of Health.

quantify the amount of funding and the number of grants received by DFMs from the NIH from 2002 to 2014 , using criteria similar to those applied by Lucan et al. ${ }^{4}$ These totals were compared with total funding (adjusted to 2014 dollars using Consumer Price Index data from the US Bureau of Labor and Statistics) and the number of projects that the NIH awards across all disciplines to obtain the proportions reported in Table 1. To provide context, we also obtained data from the NIH RePORTER on $\mathrm{NIH}$ grant submissions and success rates between 2006 and 2015. The NIH received 229,209 submissions over that time period, with a $20.6 \%$ success rate; 1,633 of those submissions came from DFMs, of which only $15.4 \%$ were successful. FM faculty submitted $0.7 \%$ of all grants but represent only $0.5 \%$ of awards. Further detail is presented in Table 2.

Our comprehensive review of the RePORTER database suggests that NIH funding to DFMs remained proportionally consistent across the study period-around $0.2 \%$ of total funding and $0.3 \%$ of total grants awarded. Study limitations include the risk of misclassification of the principal investigators' departmental affiliations and the inability to capture coinvestigator funding, though both could either inflate or reduce the reported proportion of funding and grants to DFMs.

It is apparent across all metrics evaluated here that DFMs continue to receive a small portion of awards and funding from the NIH, particularly relative to their proportion of the physician workforce in direct patient care (or health care service delivery). The degree to which these issues reflect a bias against generalist inquiry, the makeup of review committees, a lower priority on research among DFMs, or other factors is unknown. While family physicians often provide inpatient services (including roles as hospitalists, in obstetrics, and in urgent/emergency care), the main focus of FM as a specialty is on the ambulatory, outpatient setting. As such, it requires evidence to inform whole-patient, community-relevant care delivered in that setting. A plan for achieving this goal has recently been proposed. ${ }^{6}$ In addition, the "Health is Primary" campaign to envision the future of FM includes a distinct call for increasing research capacity. ${ }^{3}$ However, changing these proportions will require considerable effort to build research capacity within DFMs and their frontline practice research networks, and to shift policymaker and funder perceptions of the value of the FM research enterprise.

Table 2. Comparison of Awards Reviewed versus Awarded, for All Departments and Family Medicine Only*

\begin{tabular}{|c|c|c|c|c|c|c|}
\hline \multirow[b]{3}{*}{$\begin{array}{l}\text { Fiscal } \\
\text { Year }\end{array}$} & \multicolumn{6}{|c|}{ Applications } \\
\hline & \multicolumn{3}{|c|}{ All Departments } & \multicolumn{3}{|c|}{ Family Medicine } \\
\hline & $\begin{array}{l}\text { Reviewed } \\
\text { (n) }\end{array}$ & $\underset{(\mathrm{n})}{\text { Awarded }}$ & $\begin{array}{c}\text { Success } \\
\text { Rate } \\
(\%)\end{array}$ & $\begin{array}{c}\text { Reviewed } \\
\text { (n) }\end{array}$ & $\underset{\text { (n) }}{\text { Awarded }}$ & $\begin{array}{c}\text { Success } \\
\text { Rate } \\
(\%)\end{array}$ \\
\hline 2006 & 22,339 & 4,670 & 20.9 & 187 & 25 & 13.4 \\
\hline 2007 & 22,981 & 5,162 & 22.5 & 168 & 27 & 16.1 \\
\hline 2008 & 21,113 & 4,919 & 23.3 & 145 & 26 & 17.9 \\
\hline 2009 & 20,846 & 4,585 & 22.0 & 173 & 30 & 17.3 \\
\hline 2010 & 21,954 & 4,840 & 22.0 & 161 & 23 & 14.3 \\
\hline 2011 & 23,230 & 4,409 & 19.0 & 159 & 25 & 15.7 \\
\hline 2012 & 24,389 & 4,646 & 19.0 & 161 & 19 & 11.8 \\
\hline 2013 & 23,738 & 4,376 & 18.4 & 171 & 28 & 16.4 \\
\hline 2014 & 24,153 & 4,722 & 19.6 & 158 & 23 & 14.6 \\
\hline 2015 & 24,466 & 4,876 & 19.9 & 150 & 25 & 16.7 \\
\hline Total & 229,209 & 47,205 & 20.6 & 1,633 & 251 & 15.4 \\
\hline
\end{tabular}

*Data obtained from the NIH Research Portfolio Online Reporting Tools (RePORT). Funding. Available from: https:// report.nih.gov/success_rates/index.aspx. Accessed July 19, 2016. 


\section{References}

1. Green LA, Fryer GE Jr, Yawn BP, Lanier D, Dovey SM. The ecology of medical care revisited. N Engl J Med. 2001;344:2021-5.

2. Westfall JM, Mold J, Fagnan L. Practice-based research-"Blue Highways" on the NIH roadmap. JAMA 2007;297:403-6.

3. Phillips RL, Pugno PA, Saultz JW, et al. Health is primary: family medicine for America's health. Ann Fam Med 2014;12(Suppl 1):S1-12.
4. Lucan SC, Phillips RL Jr, Bazemore AW. Off the roadmap? Family medicine's grant funding and committee representation at NIH. Ann Fam Med 2008;6: 534-42.

5. U.S. Department of Health \& Human Services. NIH Research Portfolio Online Reporting Tools (RePORT). Available from: http://report.nih.gov/ index.aspx. Accessed December 14, 2015.

6. deGruy FV, Ewigman B, DeVoe JE, et al. A plan for useful and timely family medicine and primary care research. Fam Med 2015;47:636-42. 